Research Article

\title{
Numerical Computation of MHD Thermal Flow of Cross Model over an Elliptic Cylinder: Reduction of Forces via Thickness Ratio
}

\author{
Afraz Hussain Majeed (D), Rashid Mahmood (D), Waqas Sarwar Abbasi, and K. Usman \\ Department of Mathematics, Air University, PAF Complex E-9, Islamabad 44000, Pakistan \\ Correspondence should be addressed to Afraz Hussain Majeed; chafrazhussain@gmail.com
}

Received 30 July 2021; Revised 17 September 2021; Accepted 6 October 2021; Published 18 October 2021

Academic Editor: Akif Akgul

Copyright (C) 2021 Afraz Hussain Majeed et al. This is an open access article distributed under the Creative Commons Attribution License, which permits unrestricted use, distribution, and reproduction in any medium, provided the original work is properly cited.

\begin{abstract}
The present work is concerned with a comprehensive analysis of hydrodynamic forces, under MHD and forced convection thermal flow over a heated cylinder in presence of insulated plates installed at walls. The magnetic field is imposed in the transverse direction of flow. The Galerkin finite element (GFE) scheme has been used to discretize the two-dimensional system of nonlinear partial different equations. The study is executed for the varying range of flow behavior index ( $n$ ) from 0.4 to 1.6, Hartmann number ( $\mathrm{Ha}$ ) from 0 to 100, Reynolds number (Re) from 10 to 50, Grashof number (Gr) from 1 to 10, thickness ratio $(e)$ from 0.5 to 1.0 , and Prandtl number (Pr) from 1 to 10, respectively. A coarse hybrid computational grid is developed, and further refinement is carried out for obtaining the highly accurate solution. The optimum case selection is based on flow patterns, drag and lift coefficients, and pressure drop reduction against cylinder thickness ratios and average Nusselt numbers. Drag coefficient increases with an increase in thickness ratio $(e)$. The drag force reduction for $e=0.5$ and $e=0.75$ is also observed for a range of the power law index as compared with $e=1.0$ cylinder. Maximum pressure drop over the back and front points of cylinder is reported at $\mathrm{Ha}=100$.
\end{abstract}

\section{Introduction}

Flow around bluff bodies of various shapes is a traditional study in fluid mechanics. With Reynolds (Re), the flow characteristics vary as the vortex structure changes behind the solid body when flow is separated. The situation becomes more fascinating when the flow is coupled with heat transfer, and therefore various theoretical, experimental, and simulation-based studies are present in the literature in different convective regimes. In the presence of multiple bluff bodies, the problem is more challenging, complex, and interesting. Expeditious enhancements of the power industry introduce a new generation study that focuses mainly on the thermofluidic properties of convective force and mixed flow past multiple configurations of bluff body. Due to the interaction between vortices introduced on the cylinders, the phenomenon of shear layer transfer in these flow types provides quite different signatures (see refs. [1-13]). The flow structures and the heat transfer features of a thermal transverse rectangular heated cylinder in the cross flow are analyzed numerically by Yang and Fu [1]. Zhao et al. [2] numerically investigated the characteristics of thermal flow for the laminar jet cluster, normally impinging on a plane wall. King and Chandratilleke [3] have reported the parametric study on impinged jets arranged in both square and hexagonal arrays shapes for maximum heat transfer. Nadeem et al. [4] reported the solution of similarity of the steady flow from a second-grade boundary layer with heat transfer via a horizontal circular cylinder. Yousefifard et al. [5] presented an unstructured grid using a particular vertexbased control volume framework. Flow evaluations have been carried out using structured and unstructured grids on the basis of Reynold numbers for steady and unstable flows. Shen et al. [6] numerically investigated the effects of thermal 
features and rotational flow characteristics in ribbed channel at high Reynolds number and also computed the influence on the average Nusselt number. Zainuddin et al. [7] numerically examined the free oscillatory convection in the presence of heat generation around the horizontal circular cylinder of a Newtonian fluid by using the final differentiation method.

The broadest and most probable category of non-Newtonian fluids is pseudoplastic fluid. In these systems, the relation between viscosity and shear has an important technological effect, and a high degree of pseudoplasticity is generally undesirable because this implies poor flow at low shears. Esmaeili et al. [14] investigated that the selected nonNewtonian models are distinguished by the Carreau and Cross-Williamson models, which incorporate the tapering effects of blood flow. Xie and Jin [15] studied that the simulation of non-Newtonian free surface flow is based on the advantages of particulate methods in terms of handling large deformations and fragmentation. To capture the viscous characteristics of mixture flows, the cross-rheology equation has been chosen. Welahettige et al. [16] have numerically computed the effects of shear thinning fluid flow in an open channel. Mustafa et al. [17] have reported the rheology of cross-fluid flow over a steady rigid plate due to the flow rate gradient of pressure. Hauswirth et al. [18] simulated the effects of cross model fluid flow in permeable medium by using Lattice Boltzmann Method (LBM). A comprehensive literature review reveals that no due attention has been paid to the fluid cross that predicts the pseudoplastic nature of the fluid over a varying range of shear rate.

One of the most significant topics in the magnetohydrodynamic two-phase flows is to comprehend the motion of free fine particles under instantaneous gravity, buoyancy, hydrodynamic force, and Lorentz force. The clean metal manufacture excluding oxides and other kinds of nonmetallic inclusions is an example in electromagnetic metallurgy. If there is no magnetic field, both numerical simulations and experiments have fully investigated a solid particle generally modelled as a sphere. Sekhar et al. [19] simulated the steady and viscous fluid flux around a circular cylinder with a linear magnetic field. The multigrid procedure with deformity correction techniques is being used to obtain an accurate solution for the second order of complete nonlinear Navier-Stokes equations. Grigoriadis et al. [20] imposed a new MID configuration scheme for handling primarily MHD flows in complex domain. Tamoor et al. [21] investigated that the Newtonian MHD Casson fluid heating features are addressed by stretched cylinders moving at a linear velocity. Pan et al. [22-24] numerically investigated the effects of instability and transition of a vertical ascent or drop in a free field affected by a vertical magnetic field. Furthermore, they examined that the magnetic field can be used to destabilise the fluid solid system Chen et al. [25] numerically studied the effects of turbulent shear flow in the cylindrical container of an electrically conducting fluid. The flow is driven by the Lorentz azimuthal force, which results from a large number of small electrodes injecting the radial electrical currents on the base and the axial direction imposed magnetic field.
Flow analysis is fascinating as well as instigating. There are many technological applications and scientific challenges, but a wide range of fields requires further numerical and experimental research. The focus on frictional effects and heat exchange is on the viscous fluid flows over solid surfaces or within ducts and channels. The fluid properties must be evaluated to take into account of those effects. Either experimentally or theoretically the problem can be addressed. Various works have been proposed over the years to use numerical methods to solve incompressible Newtonian flow problems using finite differences, finite element, and finite volumes schemes. The most famous method is the classic PARDISO algorithm, which together with the pressure correction equation introduces the stalled grid concept. This method was used to resolve different $2 \mathrm{D}$ flow configurations successfully. In recent decades, three-dimensional numerical simulation of a variety of physical issues seems to have become widespread with the invention of fast, multiprocessor personal computers, including simple computer cluster management. It was noted that information still scarce is available in the literature in non-Newtonian fluid flows, especially polymer melts in molding process are evaluated in [26-32].

The aim of the present study is to compute reduction of forces based on thickness ratio (e) of elliptic obstacle submerged in cross-fluid flow. Such analysis of forces in conjunction with the cross model is new for CFD community. The rest of manuscript is organized as follows; in Section 2, flow configuration and governing equations are explained. Numerical scheme, grid convergence, and code validation are executed in Section 3. A detailed analysis of results is performed in Section 4. Finally, conclusion is mentioned in Section 5.

\section{Flow Configuration and Governing Equations}

The domain is a benchmark channel $\Omega=[0,2.2] \times[0,0.41]$ with a heated elliptic cylinder of diameter $D_{L}=0.1$ placed in it having center at $C(0.2,0.2)$ and $h$ be the half height of the channel as revealed in Figure 1 while a consistent temperature $T_{h}$ maintained on the surface of cylinder. Moreover, the thermophysical properties of fluids are considered to be free from temperature. Along the cylinder axis is imposed a homogenous vertical magnetic field with strength $B$. One of the parallel walls of the magnetic field is heated to a constant $T_{h}$ wall temperature while the other surfaces are isolated thermally. The magnetic Reynolds number, which represents the relationship between the induced and applied magnetic field, is very small for a high Hartmann number. The magnetic field induced is thus negligible, and it is imposed in the $z$-direction only by that magnetic field. Also, the effects of viscous dissipation are neglected from the heat equation.

The steady, nonisothermal, and viscous incompressible fluid flow through a wildly long heated cylinders is the govern of continuity, dynamics, and energy equations. These equations are written as follows in their nondimensional forms (see ref. [33]): 


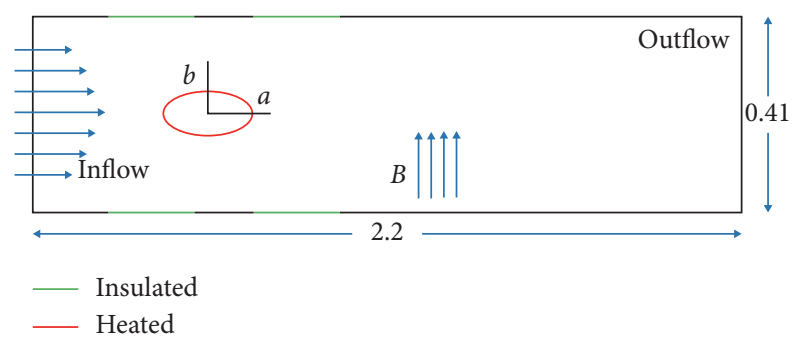

Figure 1: Schematic diagram of flow domain.

$$
\begin{aligned}
\frac{\partial u}{\partial x}+\frac{\partial v}{\partial y} & =0 \\
u \frac{\partial u}{\partial x}+v \frac{\partial u}{\partial y} & =-\frac{\partial p}{\partial x}+\frac{1}{\operatorname{Re}}\left(\frac{\partial \tau_{x x}}{\partial x}+\frac{\partial \tau_{x y}}{\partial y}\right) \\
u \frac{\partial v}{\partial x}+v \frac{\partial v}{\partial y} & =-\frac{\partial p}{\partial y}+\frac{1}{\operatorname{Re}}\left(\frac{\partial \tau_{y x}}{\partial x}+\frac{\partial \tau_{y y}}{\partial y}\right)+\frac{\mathrm{Gr}}{\operatorname{Re}^{2}} \theta-\frac{D_{L} \mathrm{Ha}}{h \operatorname{Re}} v
\end{aligned}
$$$$
u \frac{\partial \theta}{\partial x}+v \frac{\partial \theta}{\partial y}=\frac{1}{\operatorname{Re} \operatorname{Pr}}\left(\frac{\partial^{2} \theta}{\partial x^{2}}+\frac{\partial^{2} \theta}{\partial y^{2}}\right) .
$$

The velocity, pressure, and temperature $u, v, p$, and $\theta$ are nondimensional. The dimensionless aspects of the domain indicate that certain dimensional parameters, such as Reynolds, Grashof, Prandtl, and thickness ratio, govern the velocity and temperature profile in the current circumstances. The parameters are defined as follows:
(i) Grashof number $\mathrm{Gr}=g \beta\left(T_{h}-T_{0}\right) D_{L}^{3} / \mu^{2}$
(ii) Prandtl number $\operatorname{Pr}=v / \alpha$
(iii) Hartmann number $\mathrm{Ha}=\mathrm{hB} \sqrt{\sigma / \rho v}$
(iv) Thickness ratio $e=b / a$
(v) Cross-fluid model [34] $\tau=\left(\mu_{\infty++}\left(\mu_{0}-\mu_{\infty} / 1+\right.\right.$ $\left.\left.(\lambda \dot{\gamma})^{n}\right)\right) \dot{\gamma}$

All the parameters have been defined in the nomenclature section. These are complementary to the problem statement. Fluid with a parabolic profile in $x$-direction is entered at the entrance to this domain. For all variables, we set the Neumann condition at the outlet. On the other walls of the channel and on the surface of obstacle, no slip conditions have been imposed In addition, obstacles are being uniformly heated while channel walls remain cold except the plates that are insulated.

Furthermore, computational results in the form of primitive variables $(u, v, p$, and $\theta)$ from the governing equations in consonance with the abovementioned domain boundary conditions have been obtained. In addition, the derived quantities are evaluated by way of drag coefficient, lift coefficient, and average Nusselt number, respectively.

The nondimensional net drag $\left(F_{d}\right)$ and lift $\left(F_{l}\right)$ forces act on the submerged cylinder in the flow and normal direction, while the drag and lift coefficients are

$$
\begin{aligned}
C_{D} & =\frac{2 F_{d}}{\rho U_{\text {mean }}^{2} D_{L}}, \\
C_{L} & =\frac{2 F_{l}}{\rho U_{\text {mean }}^{2} D_{L}} .
\end{aligned}
$$

Here, the average velocity is $U_{\text {mean }}=2 / 3 U_{\max }$ where $U_{\max }=0.3$ be the maximum velocity of parabolic profile. One more important quantity of interest is pressure drop $\delta p=p_{L}-p_{R}$ capitalizing with the front and back point of the cylinder, respectively. The local Nusselt $\left(\mathrm{Nu}_{\text {local }}\right)$ number on the surface of cylinder and on plates is estimated by $\mathrm{Nu}_{\text {local }}=-\left(\partial \theta / \partial n_{s}\right)$. Such values have been averaged over the both surfaces (cylinder and plates) to obtain the average Nusselt $\left(\mathrm{Nu}_{\text {avg }}\right)$ number given as follows:

$$
\mathrm{Nu}_{\text {avg }}=\frac{1}{S} \int_{S} \mathrm{Nu}_{\text {local }} \mathrm{d} S \text {, }
$$

where " $S$ " and " $n_{s}$ " are the surfaces of thermal region and normal direction of the surface; it is reasonable to postulate that the drag coefficient is function of Re whereas the Nusselt number depends on the Pr.

\section{Numerical Scheme and Grid Convergence}

Because of the two-dimensional development flow territory and the nonlinearity of the cross-fluid model, analytical solutions of mass, momentum, and energy equations cannot be exhibited; therefore, a numerical scheme based on finite element discretization is used to calculate the solution for various configurations. The discretized version of nonlinear equations is linearized by the Newton method, and an efficient and robust linear solver PARDISO has been utilized for inner computations. Finite element space involving quadratic polynomials $\left(\mathbb{P}_{2}\right)$ has been selected to approximate the velocity and temperature component whereas the pressure approximation is done using the space of linear polynomials $\left(\mathbb{P}_{1}\right)$. For the computation of accurate drag and lift forces, a very fine mesh is created in the vicinity of the obstacle as shown in Figure 2. To avoid potential problems of convergence, the solution has been initialized with zero value systems of velocity and temperature at each point in the grid.

Grid independence studies were carried out by computing $\mathrm{Nu}_{\text {avg }}$ for all cases of thickness ratio (e), and the results are presented in Tables $1-3$. The values of other parameters are set as $n=1, \mathrm{Ha}=0, \operatorname{Re}=20, \operatorname{Pr}=6.2$, and $\mathrm{Gr}=10$. A regular grid refinement is performed for all the three meshes from level 1 to level 8. No significant changes in $N u_{\text {avg }}$ were observed with further grid refinement at higher levels in space. All results were therefore calculated at mesh level 8. The corresponding number of element (\#EL) and degree of freedom (\#DOF) is provided in Tables 1-3.

The code has also been validated for steady flow in order to strengthen the reliability of the results to be achieved for the proposed study. Finally, the current code has also been validated against the study by Mahmood et al. [31] in Table 4. 


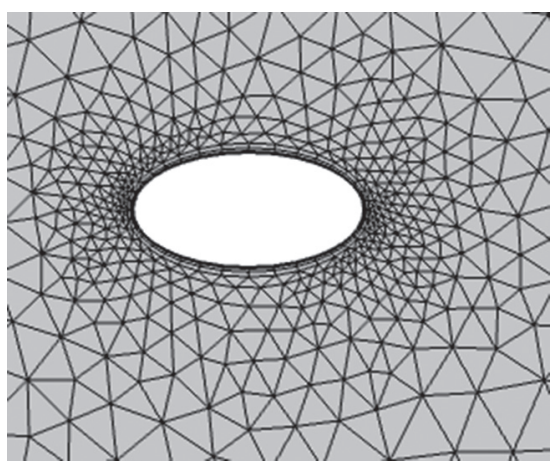

(a)

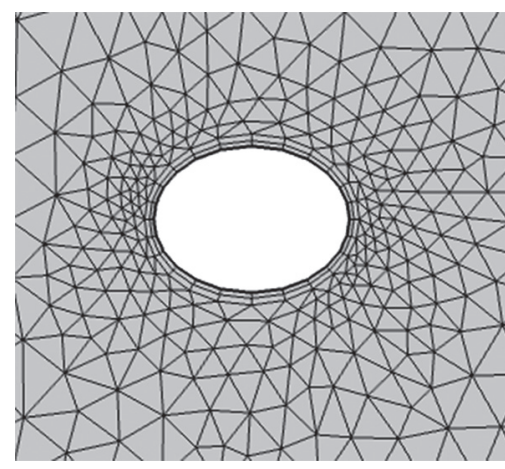

(b)

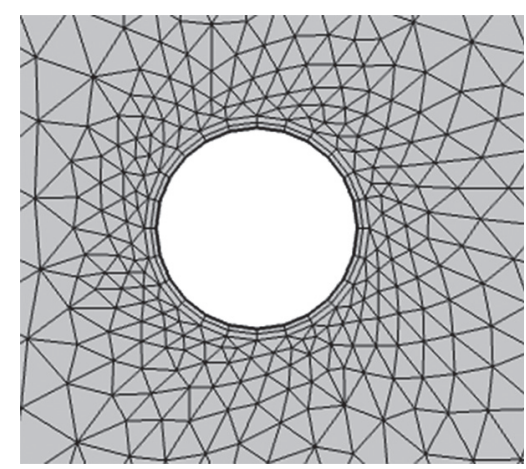

(c)

FIgure 2: Computational hybrid grid at coarse level: (a) $e=0.5$; (b) $e=0.75$; (c) $e=1.0$.

TABLE 1: Grid convergence study for $e=0.5$.

\begin{tabular}{lccr}
\hline Refinement level & \#EL & \#DOF & $N u_{\text {avg }}$ \\
\hline 1 & 1156 & 8733 & 5.5884 \\
2 & 1790 & 13404 & 5.6196 \\
3 & 2806 & 20530 & 5.6428 \\
4 & 4976 & 35659 & 5.6511 \\
5 & 7314 & 51641 & 5.652 \\
6 & 12562 & 86773 & 5.6562 \\
7 & 27892 & 191815 & 5.6577 \\
8 & 64922 & 442155 & 5.6582 \\
\hline
\end{tabular}

TABLE 2: Grid convergence study for $e=0.75$.

\begin{tabular}{lccr}
\hline Refinement level & \#EL & \#DOF & $\mathrm{Nu}_{\text {avg }}$ \\
\hline 1 & 1054 & 8023 & 5.8913 \\
2 & 1606 & 12113 & 5.8991 \\
3 & 2570 & 18901 & 5.9863 \\
4 & 4584 & 32968 & 6.0024 \\
5 & 6840 & 48417 & 6.0026 \\
6 & 12154 & 83978 & 6.0169 \\
7 & 26916 & 185471 & 6.0276 \\
8 & 64862 & 441909 & 6.0291 \\
\hline
\end{tabular}

TABle 3: Grid convergence study for $e=1.0$.

\begin{tabular}{lccc}
\hline Refinement level & \#EL & \#DOF & $\mathrm{Nu}_{\text {avg }}$ \\
\hline 1 & 948 & 7287 & 6.0562 \\
2 & 1584 & 11970 & 6.2515 \\
3 & 2414 & 17840 & 6.3187 \\
4 & 4562 & 32826 & 6.3668 \\
5 & 6668 & 47299 & 6.3674 \\
6 & 11886 & 82188 & 6.3774 \\
7 & 27196 & 187387 & 6.3969 \\
8 & 65518 & 446365 & 6.3992 \\
\hline
\end{tabular}

\section{Results and Discussion}

In this section, the computational results for dimensionless equations (1)-(4) are presented. The values of cross model parameters, namely, $\mu_{\infty}, \mu_{o}$, and $\lambda$ are taken from [34]. The pure
TABLE 4: Validation of code for comparison of drag and lift coefficients for $e=1.0$ (circular) cylinder.

\begin{tabular}{lccc}
\hline $\begin{array}{l}\text { Fluid } \\
\text { forces }\end{array}$ & Mahmood et al. [31] & $\begin{array}{c}\text { Cold } \\
\text { cylinder }\end{array}$ & $\begin{array}{c}\text { Heated } \\
\text { cylinder }\end{array}$ \\
\hline$C_{D}$ & 5.5785 & 5.5785 & 5.5785 \\
$C_{L}$ & 0.0106 & 0.0106 & -0.0007 \\
\hline
\end{tabular}

hydrodynamic flow and temperature properties are obtained in Figures 3 and 4 before imposing the magnetic effects. Figures 3 and 4 show velocity profile and isotherm contours for different thickness ratios in the vicinity of the cylinder and without the effect of the magnetic field $\mathrm{Ha}=0, \mathrm{Re}=20, \operatorname{Pr}=5$, and $\lambda=0$ (Newtonian) externally used. The usual steady flow nature and the thermal fields are shown. Behind the cylinder forms a closed, steady recirculating area composed of vortices. The isotherms appear symmetrical in the wake region around the symmetry 


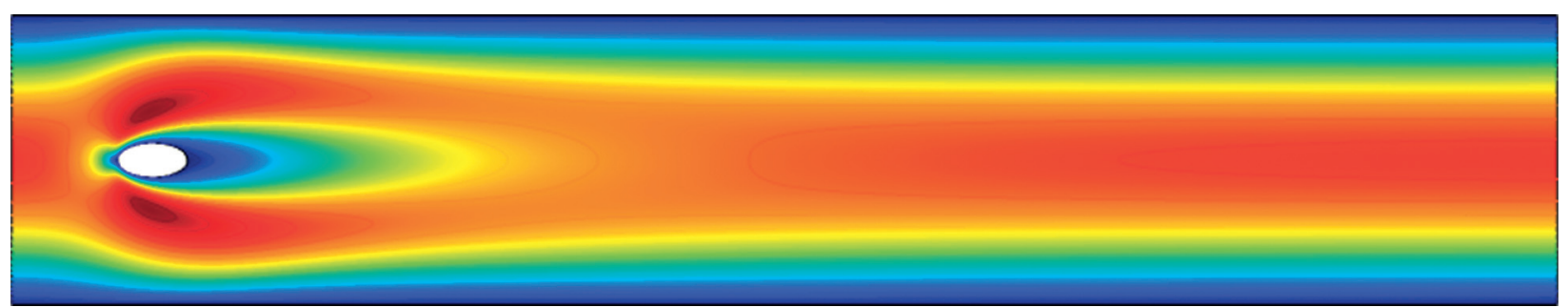

(a)

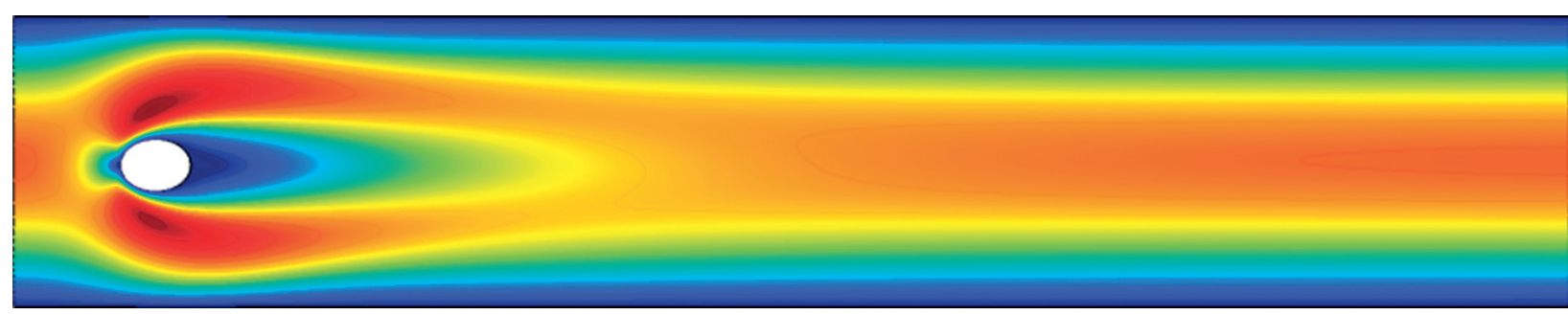

(b)

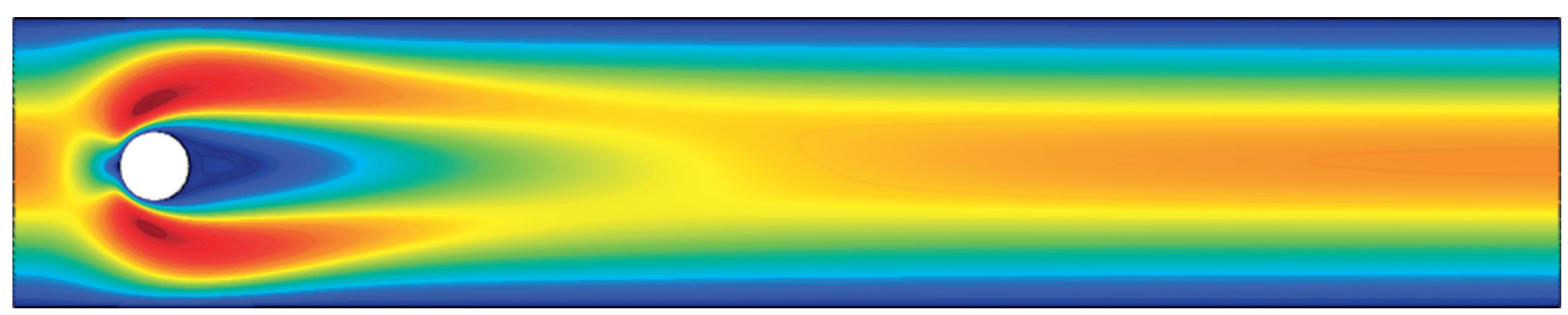

(c)

FIgURE 3: Shape effects on velocity profile for different $e$ with $\operatorname{Re}=20, \operatorname{Pr}=5$, and $\mathrm{Ha}=0$ : (a) $e=0.5 ;(\mathrm{b}) e=0.75 ;(\mathrm{c}) e=1.0$.

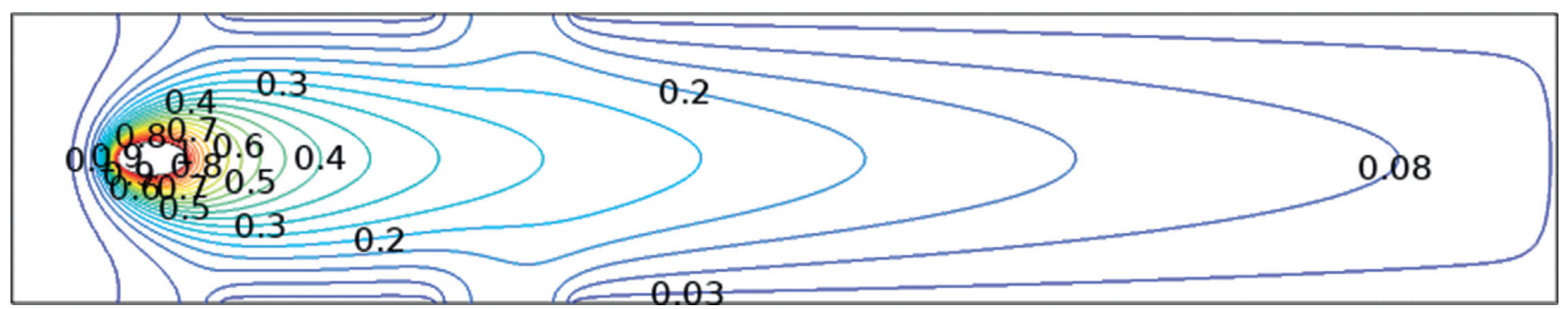

(a)

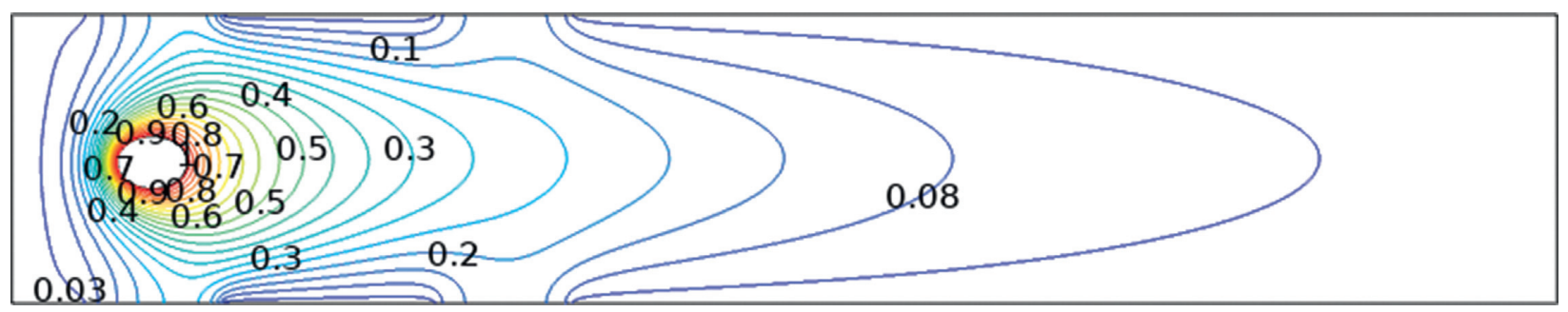

(b)

FIgURE 4: Continued. 


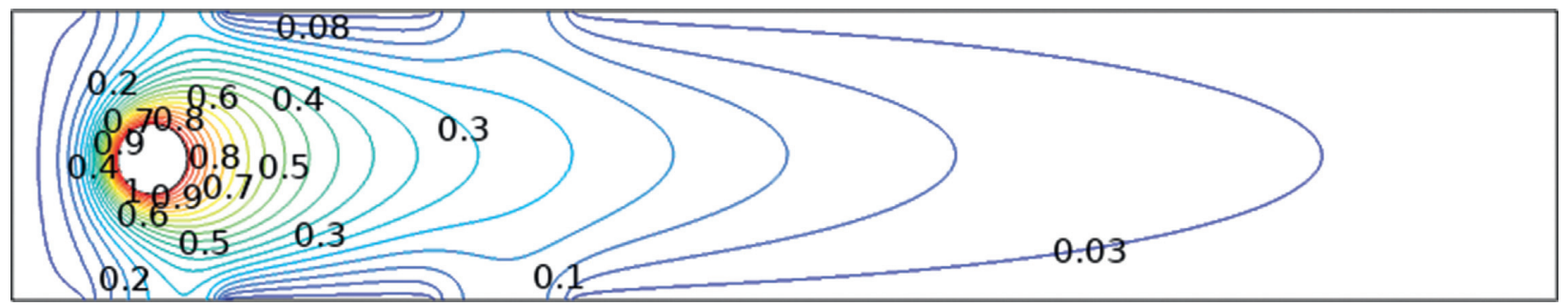

(c)

Figure 4: Shape effects on isotherm profile for different $e$ with $\operatorname{Re}=20, \operatorname{Pr}=5$, and $\mathrm{Ha}=0$ : (a) $e=0.5$; (b) $e=0.75$; (c) $e=1.0$.
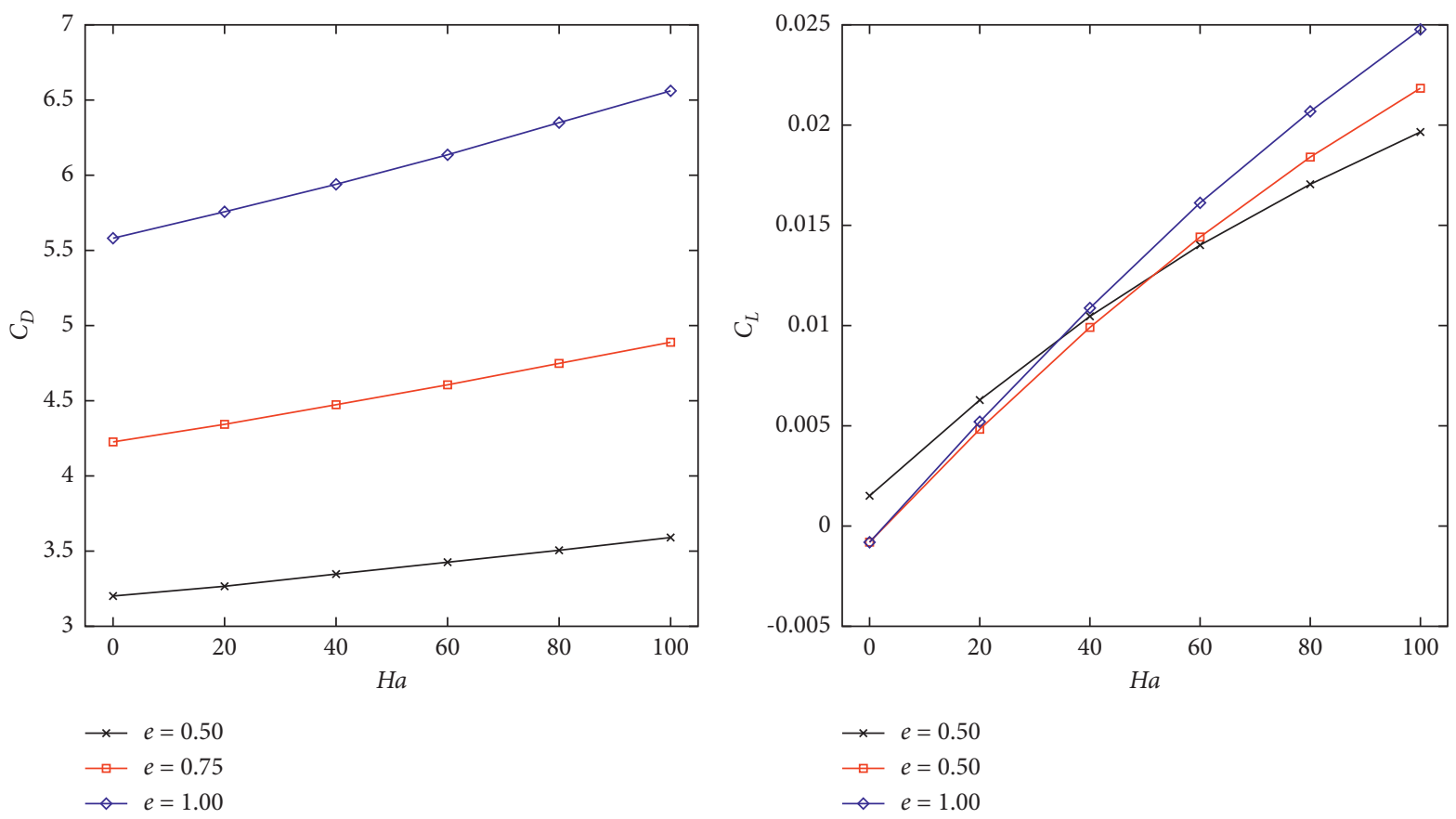

FIGURE 5: Shape effects on drag and lift coefficients against Ha for different $e$ with $\mathrm{Re}=20$.

line. The isothermal plots indicate that in the near-wake area, temperature contours are lower with an increasing thickness ratio $e$. These figures also indicate that the cylinders' front surface is the most isothermal clustering, resulting in high thermal gradients compared with some other points on the cylinder surface. One of the main objectives is to determine the complete heat transfer from the isothermal cylinder to the fluid By analyzing the heat transfer rate of the cylinder, the efficacy of the flow behavior particularly on heat exchange can be reported.

A majority of flow parameters including the drag coefficient, lift coefficient, and pressure drop have been computed in order to acquire the quantitative view of the aforementioned effects. Figure 5 shows variation of the drag and lift coefficients for various $e$ against the Hartmann number Ha. In addition, with increase in both the Hartmann number $\mathrm{Ha}$ and $e$ at fixed Re, drag coefficient increases. Moreover, lift coefficient increases with the increase in $e$ for $\mathrm{Ha} \geq 40$, while lift coefficients in the lateral direction for $\mathrm{Ha} \leq 40$ are suppressed. In Figure 6, different values of Re are illustrated for the effects of $e$ versus drag and lift coefficients. It is observed that the drag coefficient decreases while the lift coefficient increases due to viscous forces in order to enhance Re. Figure 7 demonstrates the effects on drag and lift coefficients of the Hartmann number $\mathrm{Ha}$ and Reynolds number Re. Drag and lift coefficients are expected to increase with the increase in the Hartmann number $\mathrm{Ha}$ as drag coefficients decrease and lift coefficients increase for increasing Re. Figures 8 and 9 show that eccentricity influences on drag and lift coefficients against Prandtl numbers Pr and Grashof number Gr. Furthermore, drag is increased due to increased viscosity, while lift decreases against both thermal quantities Pr and Gr numbers.

The addition of one or more cylinders to the single body has been shown to significantly impact fluid forces according to earlier research. In this study, we also focused at this phenomenon. For this purpose, for every single combination of multiple cylinders examined in this study, a percentage reduction is calculated related to the circular cylinder for the drag coefficient, the lift coefficient, and the pressure drop of 

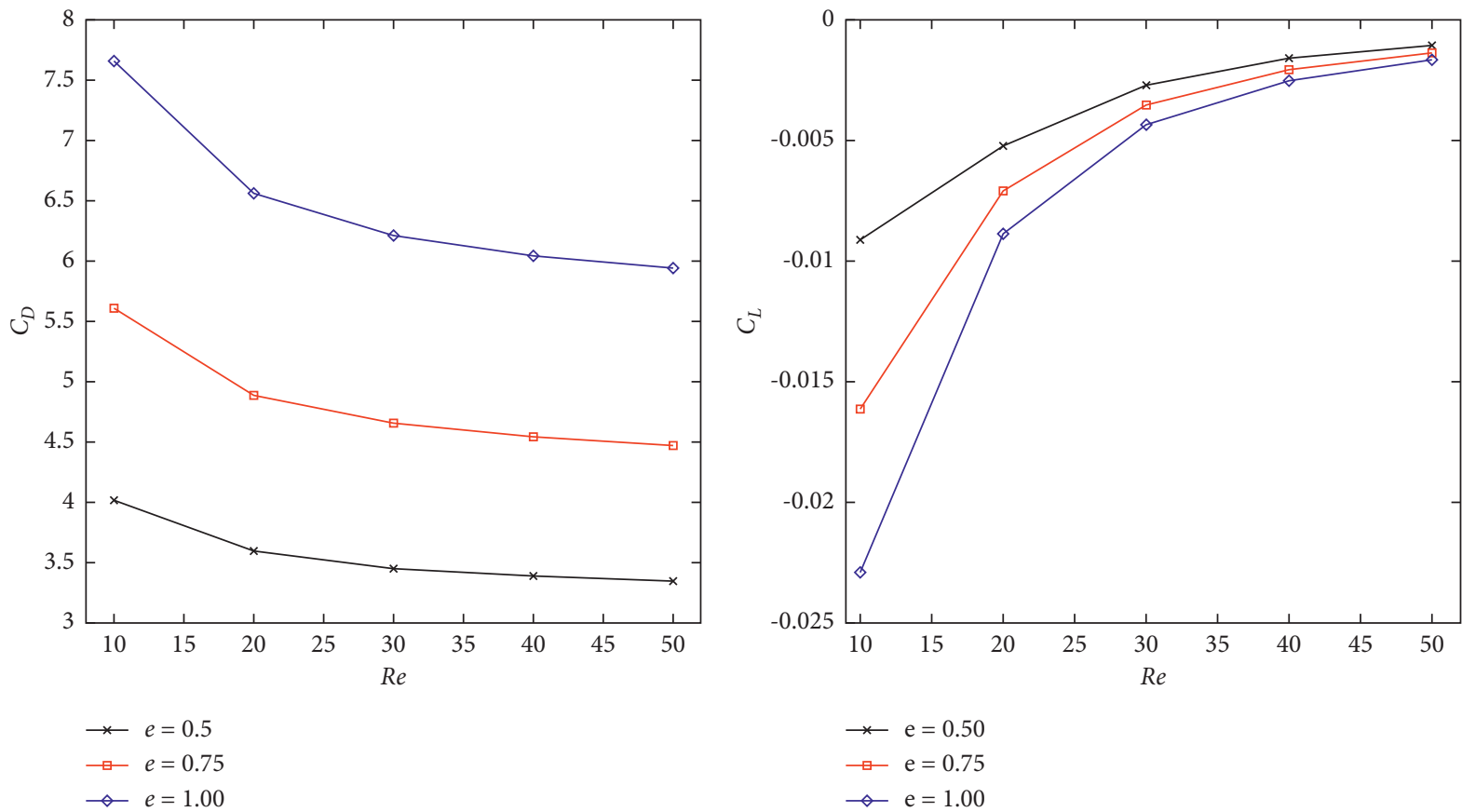

FIGURE 6: Shape effects on drag and lift coefficients against Re for different $e$ with $\mathrm{Ha}=20$.
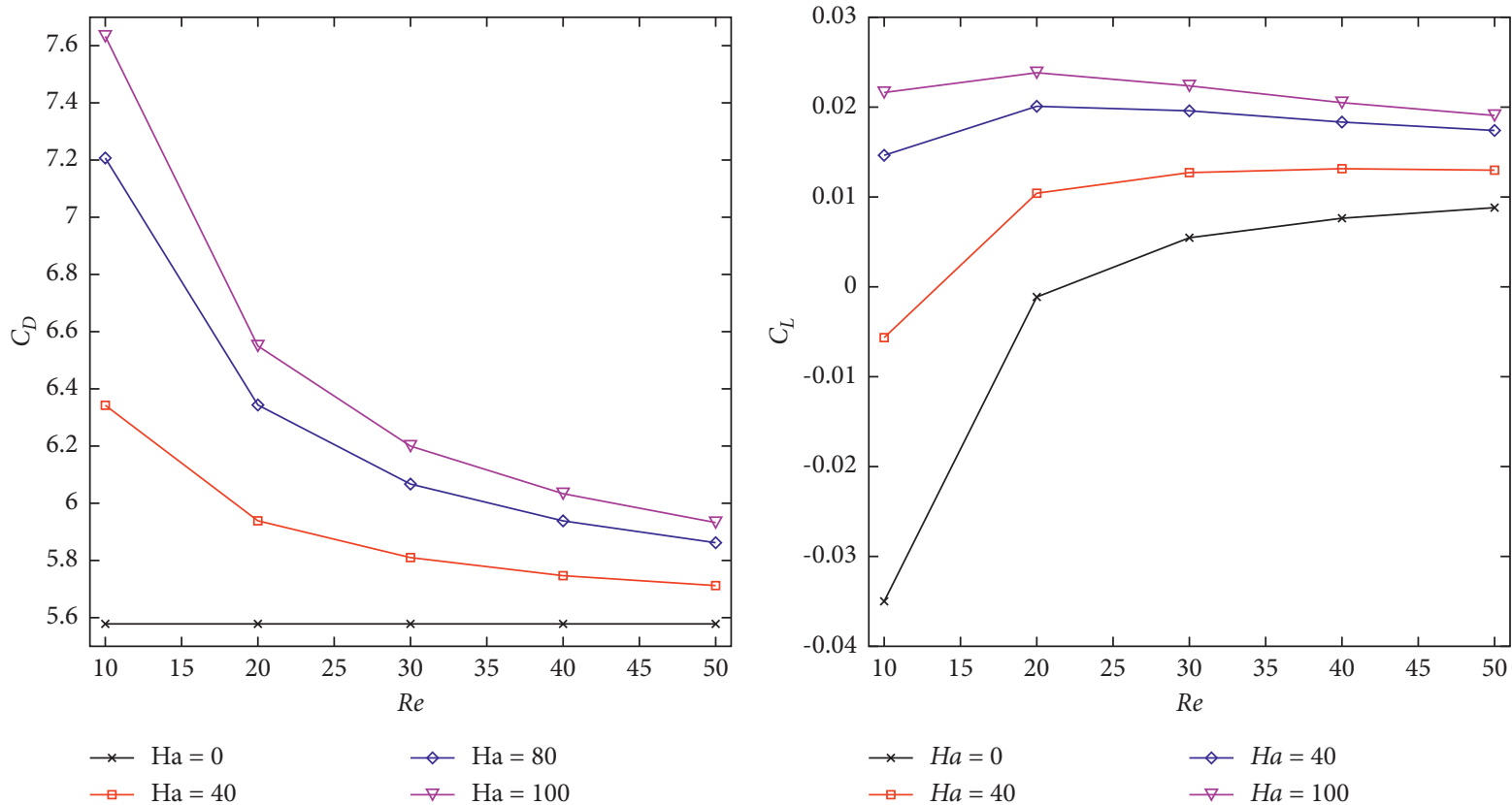

Figure 7: Impacts on drag and lift coefficients against Re for different Ha with $\mathrm{Gr}=1$ and $\mathrm{Pr}=5$.

the circular cylinder $(e=1)$. Tables 5-7 show the data of percentage reduction in drag, lift, and pressure drop for $n$ verses thickness ratio $(e)$ at fixed values of $\mathrm{Re}$ and $\mathrm{Ha}$. Maximum reduction in drag and lift coefficients is reported at $(e=0.5)$ as compared with other values of $(e)$ while for the pressure drop, highest reduction is seen at $(e=0.75)$. We may conclude that the more elliptical the bodies are, the greater will be the reduction in the strength of the wake. Table 8 displays the impact of Ha on pressure drop against $e$, and it is observed that for a fixed Ha, reduction is high for $e=0.5$; however, for a fixed thickness ratio $e$, the reduction is directly proportional to Ha. Moreover, reduction in pressure drop is inversely related with Re as evident from Table 9.

While the velocity profile and isothermal contours represent the flow and temperature fields visually, they help to delineate the local hot/cold region that is relevant to the handling of temperature sensitive materials, sensitive materials in process 

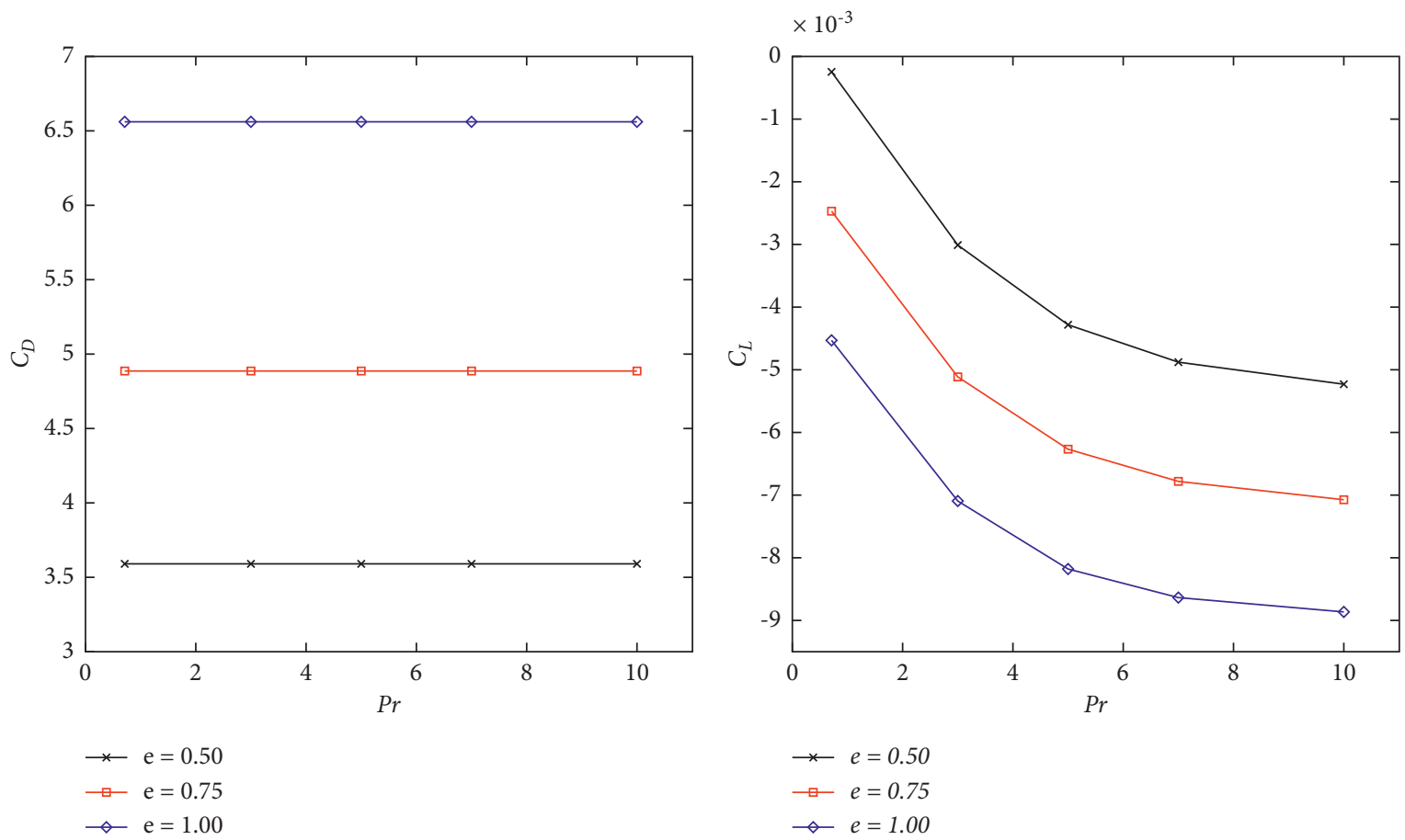

Figure 8: Impacts on drag and lift coefficients against Pr for different $e$ with $\mathrm{Gr}=1$ and $\mathrm{Ha}=20$.
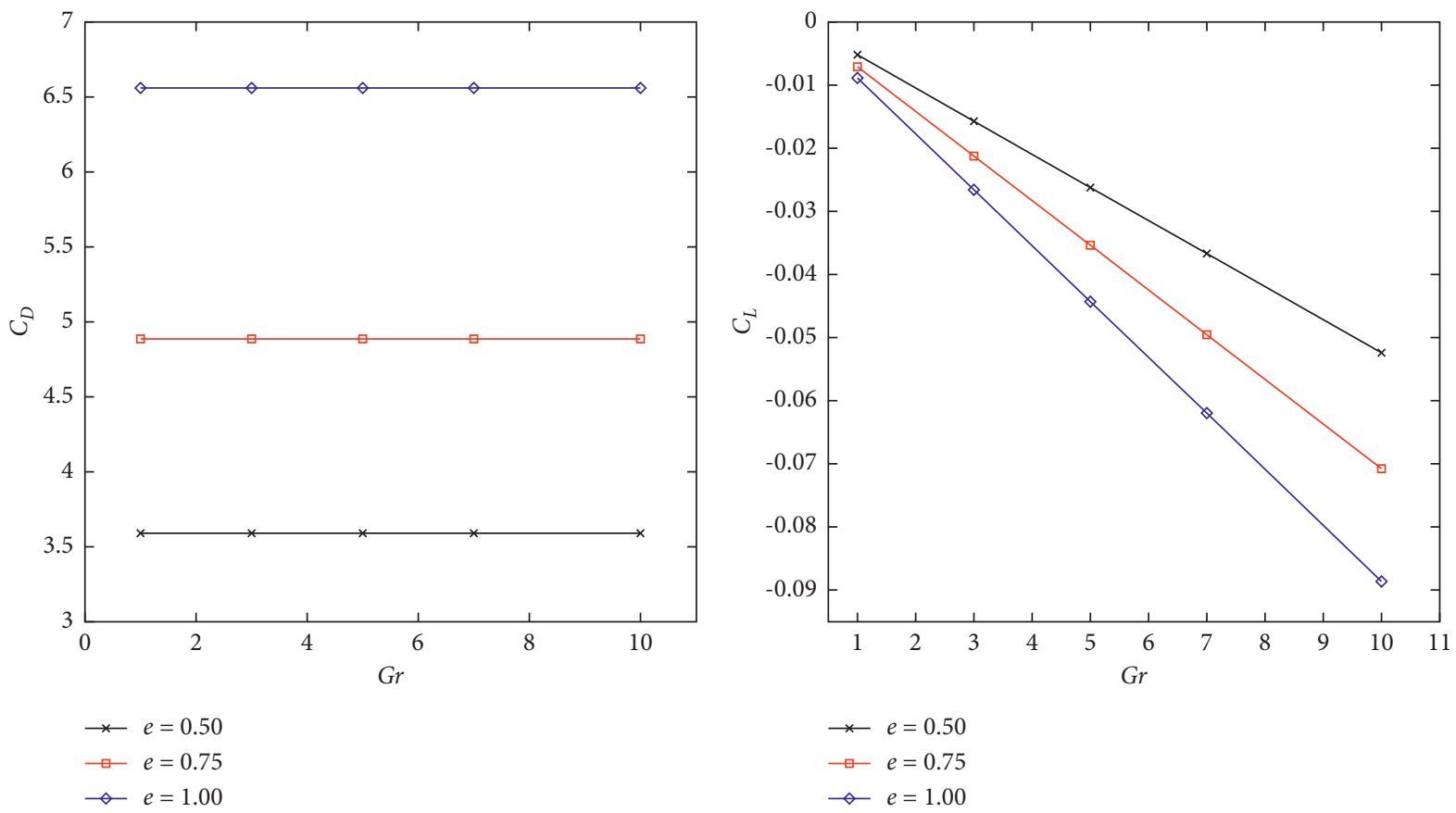

Figure 9: Impacts on drag and lift coefficients against Gr for different $e$ with $\mathrm{Pr}=5$ and $\mathrm{Ha}=20$.

engineering and calculations require accurate heat transfer coefficient given by average Nusselt number $\mathrm{Nu}_{\mathrm{avg}}$. Figure 10 illustrates functional dependence on Reynolds number, Prandtl number, and Grashof number for the average Nusselt number. Under all circumstances, the average Nusselt number is strong for the value of $e$ as set out in the previous section according to
Re, Pr, and Gr. The increasing thickness ratios $e$ also endorse the heat transfer rate due to a reduction in efficient fluid viscosity at or near the cylindrical surface. For analysis, steady flow is considered in a two-dimensional space. The speed impact for both $\mathrm{Re}$ and Hartmann number $\mathrm{Ha}$ is marked exactly at $(x=2)$, and components $u$ and $v$ are considered for minute 
TABLE 5: Influence on percentage reduction in drag $e=1.0$ for $e=0.75$ and $e=0.5$ at $\operatorname{Re}=20$ and $\mathrm{Ha}=20$.

\begin{tabular}{lccccc}
\hline$n$ & $e=1.0$ & $e=0.75$ & \% reduction & $e=0.5$ & \% reduction \\
\hline 0.4 & 5.356412 & 4.070569 & 24.00 & 3.101553 & 3.113913 \\
0.6 & 5.378040 & 4.086737 & 24.01 & 3.126193 & 42.09 \\
0.8 & 5.399516 & 4.102802 & 24.02 & 3.138408 \\
1.0 & 5.420852 & 4.118770 & 24.02 & 3.150560 & 42.10 \\
1.2 & 5.442058 & 4.134651 & 24.02 & 3.162652 & 42.10 \\
1.4 & 5.463141 & 4.150447 & 24.03 & 3.174686 \\
1.6 & 5.484107 & 4.166163 & 24.03 & 42.11 \\
\hline
\end{tabular}

TABLE 6: Influence on percentage reduction in lift coefficient for $e$ against $n$ with $\mathrm{Re}=20$ and $\mathrm{Ha}=20$.

\begin{tabular}{lccccc}
\hline$n$ & $e=1.0$ & $e=0.75$ & \% reduction & $e=0.5$ & \% reduction \\
\hline 0.4 & -0.01219 & -0.0105 & 13.86 & -0.00875 & 28.22 \\
0.6 & -0.01219 & -0.0105 & 13.86 & -0.00874 & 28.30 \\
0.8 & -0.01219 & -0.0105 & 13.86 & -0.00874 & 28.30 \\
1 & -0.01219 & -0.0105 & 13.86 & -0.00874 & 28.30 \\
1.2 & -0.0122 & -0.0105 & 13.93 & -0.00874 & 28.36 \\
1.4 & -0.0122 & -0.0105 & 13.93 & -0.00873 & 28.44 \\
1.6 & -0.0122 & -0.0105 & 13.93 & -0.00873 & 28.44 \\
\hline
\end{tabular}

TABle 7: Influence on percentage reduction in pressure drop for $e$ against $n$ with $\mathrm{Re}=20$ and $\mathrm{Ha}=20$.

\begin{tabular}{lccccc}
\hline$N$ & $e=1.0$ & $e=0.75$ & \% reduction & $e=0.5$ & \% reduction \\
\hline 0.4 & 0.11538 & 0.107049 & 7.22 & 0.107986 \\
0.6 & 0.115567 & 0.10723 & 7.21 & 0.108229 & 6.41 \\
0.8 & 0.115753 & 0.10741 & 7.21 & 0.108471 & 0.108715 \\
1.0 & 0.115938 & 0.107591 & 7.20 & 0.108959 & 6.29 \\
1.2 & 0.116122 & 0.107771 & 7.19 & 0.109203 & 6.23 \\
1.4 & 0.116306 & 0.107951 & 7.18 & 0.109448 \\
1.6 & 0.116489 & 0.108131 & 7.17 & 6.11 \\
\hline
\end{tabular}

TABLE 8: Impact of Haon reduction in pressure drop for different $e$.

\begin{tabular}{lccccc}
\hline $\mathrm{Ha}$ & $e=1.0$ & $e=0.75$ & \% reduction & $e=0.5$ & \% reduction \\
\hline 0 & 0.117615 & 0.111998 & 4.76 & 0.109765 & 6.67 \\
20 & 0.119741 & 0.113753 & 5.00 & 0.111084 & 7.23 \\
40 & 0.122249 & 0.115795 & 5.28 & 0.112615 & 7.88 \\
80 & 0.128146 & 0.118536 & 7.50 & 0.116157 & 9.36 \\
100 & 0.131421 & 0.120145 & 8.58 & 0.118102 & 10.13 \\
\hline
\end{tabular}

TABLE 9: Impact of Re on reduction in pressure drop for different $e$.

\begin{tabular}{lccccc}
\hline $\operatorname{Re}$ & $e=1.0$ & $e=0.75$ & \% reduction & $e=0.5$ & \% reduction \\
\hline 10 & 0.122247 & 0.112795 & 7.73 & 0.112615 & 7.68 \\
20 & 0.119741 & 0.110753 & 7.51 & 0.111084 & 7.23 \\
30 & 0.118987 & 0.110133 & 7.44 & 0.110619 & 7.03 \\
40 & 0.118626 & 0.109836 & 7.41 & 0.110396 \\
50 & 0.118415 & 0.109662 & 7.39 & 0.110265 & 6.94 \\
\hline
\end{tabular}

analysis. The Reynolds number effect $(\mathrm{Re})$ against $u$ and $v$ velocities on the $(x=2)$ channel is displayed in Figure 11. A fluctuation for all Re values is observed in the $v$-velocity. Now, for $u$-velocity, the parabolic forms with overlaps are again found and the terminal velocity is 0.3 (approximately). Plots indicate the reliance on $\mathrm{Re}$ and $\mathrm{Ha}$ on stream lines. The fluidity becomes much higher for $\mathrm{Ha}$ than the rest of $\mathrm{Ha}$. The progressive increase in nonlinearity due to increase in $\mathrm{Ha}$ is seen in Figure 12. 

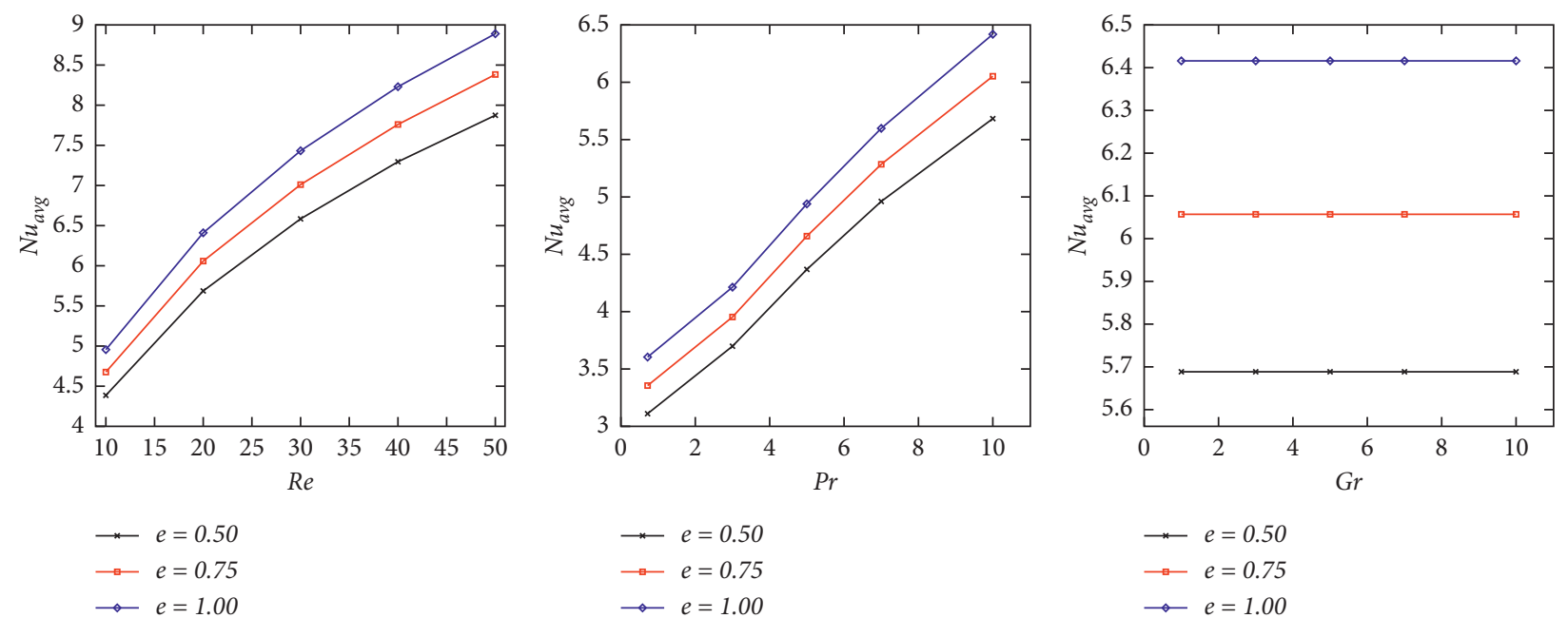

(a)

$\rightarrow e=0.50$
$\multimap e=0.75$
$\multimap e=1.00$

(b) (c)

FIGURE 10: Impacts on the average Nusselt number against different parameters for different $e$ : (a) Re; (b) Pr; (c) Gr.
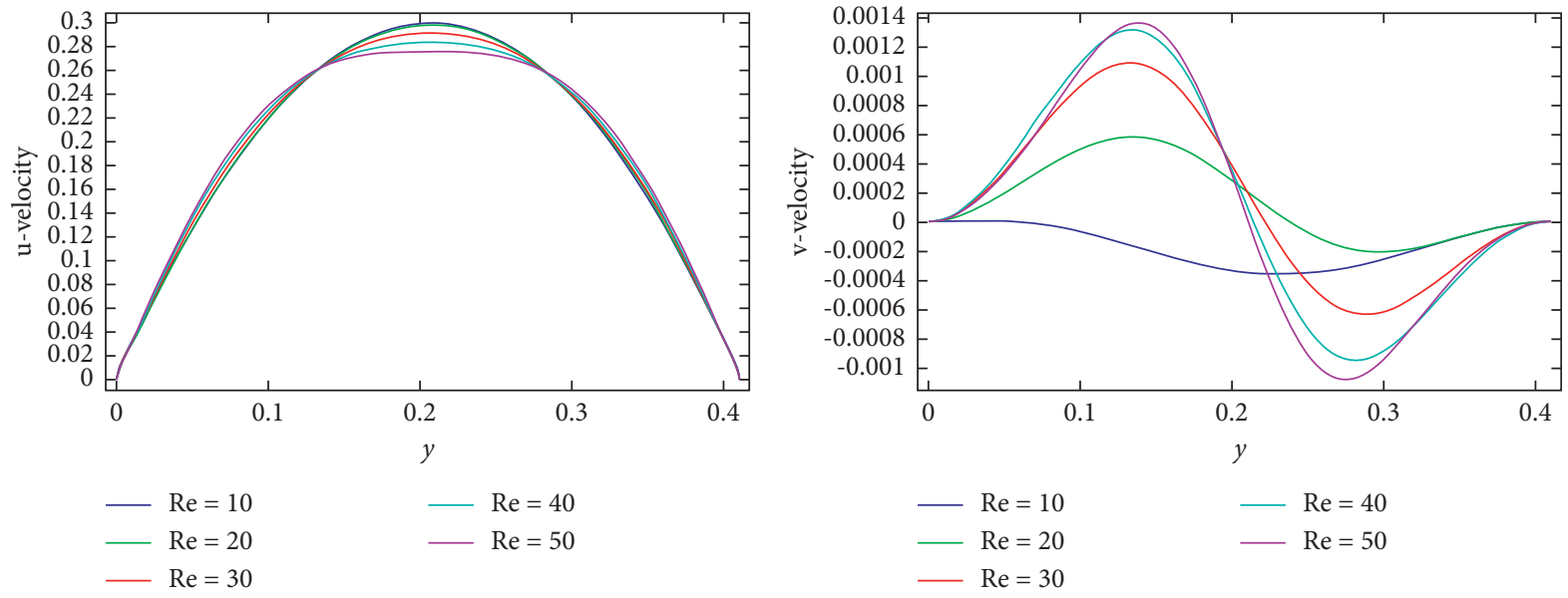

FIGURE 11: Impact on velocity line profile for different Re at $x=2$ over circular cylinder with $\mathrm{Ha}=20$.
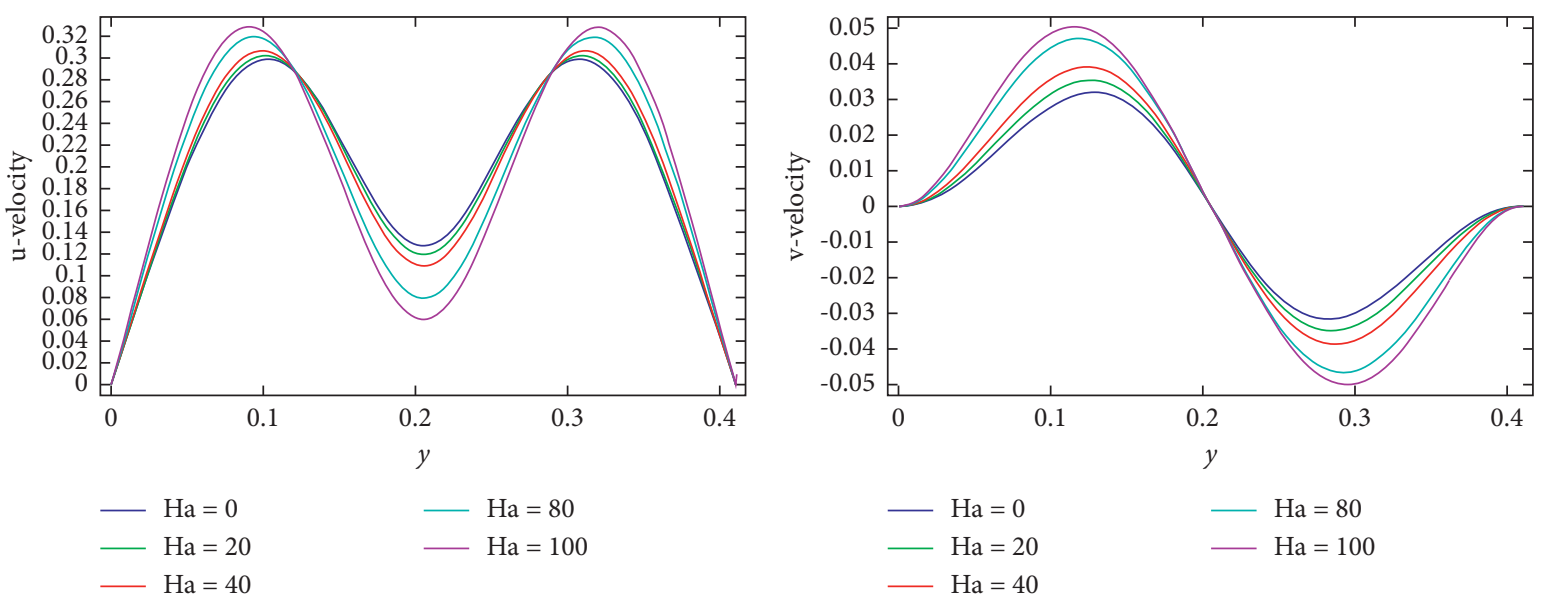

FIGURE 12: Impact on velocity line profile for different $\mathrm{Ha}$ at $x=2$ over circular cylinder with $\mathrm{Re}=20$. 


\section{Conclusions}

The present numerical work is concerned with the investigation of the flow past an elliptic cylinder for various thickness ratios $(e)$. The objective was to see the reduction in hydrodynamic forces in comparison with $e$ and heat transfer characteristics in presence of magnetic field. Simulations have been performed on the different scale of the flow behavior index $(n)$ from 0.4 to 1.6, Hartmann number (Ha) from 0 to 100, Reynolds number (Re) from 10 to 50, Grashof number (Gr) from 1 to 10, Prandtl number $(\operatorname{Pr})$ from 1 to 10 , and the thickness ratio $(e)$ from 0.5 to 1.0 . The key results of this study are concluded as follows:

(i) Reynolds number $(\mathrm{Re})$ is instrumental in investigating the phenomenon of flow and heat transfer. The flow comportment changes from slower to quicker mode as it increases.

(ii) On a heated cylinder, the average Nusselt number $\mathrm{Nu}_{\mathrm{avg}}$ is rising. At $e=1$, the maximum heat transfer was found.

(iii) The pressure drop significantly reduced by $10.13 \%$ at $\mathrm{Ha}=100$ and increases the pressure on the circular $(e=1)$ cylinders.

(iv) By enhancing thickness ratio (e), the lift coefficient $\left(C_{L}\right)$ enriches and drag coefficient $\left(C_{D}\right)$ decreases all values of significant factors.

(v) $\mathrm{Nu}_{\text {avg }}$ increases with thickness ratio (e).

(vi) For a fixed (e), reduction in pressure drop is directly proportional to $\mathrm{Ha}$ whereas it is inversely related with Re.

The current work can be extended to a nonstationary framework at high Re giving raise to periodic flows and vortex shedding behind the obstacles.

Greek Symbols

\section{Nomenclature}

$\mathrm{u}, \mathrm{v}$ : Dimensionless velocity components

$\theta: \quad$ Dimensionless temperature

$p: \quad$ Dimensionless pressure

$n$ : $\quad$ Flow behavior index

$D_{L}: \quad$ Diameter of cylinder

$L_{D}$ : $\quad$ Reference length

$\mu_{o}$ : $\quad$ Viscosity at zero shear rate

$\mu_{\infty}: \quad$ Viscosity at infinite shear rate

$\tau: \quad$ Stress tensor

$\dot{\gamma}: \quad$ Shear rate

$U_{\text {mean }}$ : Reference velocity

Re: $\quad$ Reynolds number

$h$ : Height of half channel

Pr: $\quad$ Prandtl number

Gr: Grashof number

$F_{D}: \quad$ Drag force

$C_{D}: \quad$ Drag coefficient

$F_{L}: \quad$ Lift force

$C_{L}: \quad$ Lift coefficient

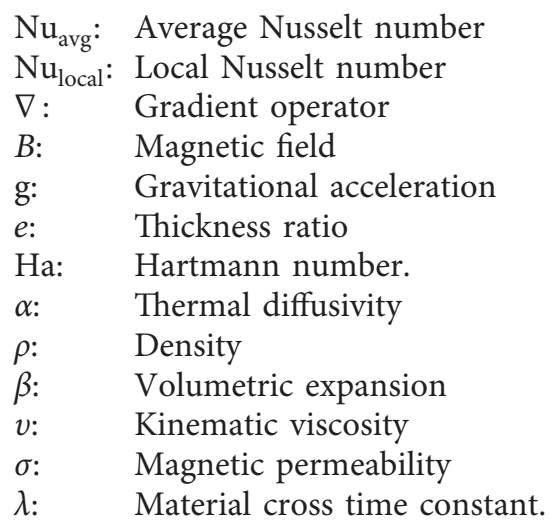

\section{Abbreviations and Acronyms}

\#EL: $\quad$ Number of elements

\#DOF: Number of degrees of freedom.

\section{Data Availability}

The relevant author can provide the data supporting the main findings of this numerical study upon request.

\section{Conflicts of Interest}

The authors declare that there are no conflicts of interest.

\section{Acknowledgments}

This work was supported by HEC-Pakistan through NRPU Project no. 14038.

\section{References}

[1] S.-J. Yang and W.-S. Fu, "Numerical investigation of heat transfer from a heated oscillating rectangular cylinder in a cross flow," Numerical Heat Transfer: Applications, vol. 39, no. 6, pp. 569-591, 2001.

[2] W. Zhao, K. Kumar, and A. S. Mujumdar, "Impingement heat transfer for a cluster of laminar impinging jets issuing from noncircular nozzles," Drying Technology, vol. 23, no. 1-2, pp. 105-130, 2005.

[3] A. J. C. King and T. T. Chandratilleke, "Heat transfer characteristics in impinging jet arrays," Australian Journal of Mechanical Engineering, vol. 4, no. 1, pp. 59-64, 2007.

[4] S. Nadeem, A. Rehman, C. Lee, and J. Lee, "Boundary layer flow of second grade fluid in a cylinder with heat transfer," Mathematical Problems in Engineering, vol. 2012, Article ID 640289, 13 pages, 2012.

[5] M. Yousefifard, P. Ghadimi, and R. Zamanian, "Unstructured grid solutions for incompressible laminar flow over a circular cylinder using a particular finite volume-finite element method," Journal of Engineering, vol. 2013, Article ID 795237, 9 pages, 2013.

[6] Z. Shen, Y. Xie, D. Zhang, and G. Xie, "Numerical calculations on flow and heat transfer in smooth and ribbed two-pass square channels under rotational effects," Mathematical Problems in Engineering, vol. 2014, Article ID 981376, 7 pages, 2014. 
[7] N. Zainuddin, M. Ismoen, R. Roslan, and I. Hashim, "Oscillatory free convection about a horizontal circular cylinder in the presence of heat generation," Mathematical Problems in Engineering, vol. 2014, Article ID 946495, 8 pages, 2014.

[8] Y. Fu, X. Zhao, X. Wang, and F. Cao, "Computation of flow past an in-line oscillating circular cylinder and a stationary cylinder in tandem using a CIP-based model," Mathematical Problems in Engineering, vol. 2015, Article ID 568176, 9 pages, 2015.

[9] S. Ajith Kumar, S. A. Lal, and A. Sameen, "Flow past a moderately heated horizontal cylinder at low Reynolds number," Proceedings of the Institution of Mechanical Engineers-Part G: Journal of Aerospace Engineering, vol. 230, no. 7, pp. 1224-1239, 2016.

[10] P. Welahettige, C. Berg, J. Lundberg, B. Lie, and K. Vaagsaether, "Computational fluid dynamics study of the effects of drill cuttings on the open channel flow," International Journal of Chemical Engineering, vol. 2019, Article ID 6309261, 9 pages, 2019.

[11] F. Hussain, A. Hussain, and S. Nadeem, "Thermophoresis and brownian model of pseudo-plastic nanofluid flow over a vertical slender cylinder," Mathematical Problems in Engineering, vol. 2020, Article ID 8428762, 10 pages, 2020.

[12] S. Bilal, A. H. Majeed, R. Mahmood, I. Khan, A. H. Seikh, and E.-S. M. Sherif, "Heat and mass transfer in hydromagnetic second-grade fluid past a porous inclined cylinder under the effects of thermal dissipation, diffusion and radiative heat flux," Energies, vol. 13, no. 1, 2020.

[13] A. H. Majeed, S. Bilal, R. Mahmood, and M. Y. Malik, "Heat transfer analysis of viscous fluid flow between two coaxially rotated disks embedded in permeable media by capitalizing non-Fourier heat flux model," Physica A: Statistical Mechanics and its Applications, vol. 540, 2020.

[14] M. Esmaeili, A. Javadzadegan, and S. E. Marashi, "The modeling of pulsatile blood flow as cross-williamson and carreau fluids in an artery with a partial occlusion," in Proceedings of the 2008 Second UKSIM European Symposium on Computer Modeling and Simulation, pp. 191-196, Liverpool, UK, September 2008.

[15] J. Xie and Y.-C. Jin, "Parameter determination for the cross rheology equation and its application to modeling nonNewtonian flows using the WC-MPS method," Engineering Applications of Computational Fluid Mechanics, vol. 10, no. 1, pp. 111-129, 2016.

[16] P. Welahettige, B. Lie, and K. Vaagsaether, "Computational fluid dynamics study of shear thinning fluid (drilling fluid) viscosity models in an open venturi channel," International Journal of Petroleum Science and Technology, vol. 13, no. 1, pp. 9-20, 2019.

[17] M. Mustafa, A. Sultan, and M. Rahi, "Pressure-driven flow of cross fluid along a stationary plate subject to binary chemical reaction and arrhenius activation energy," Arabian Journal for Science and Engineering, vol. 44, no. 6, pp. 5647-5655, 2019.

[18] S. C. Hauswirth, C. A. Bowers, C. P. Fowler et al., "Modeling cross model non-Newtonian fluid flow in porous media," Journal of Contaminant Hydrology, vol. 235, no. August, Article ID 103708, 2020.

[19] T. V. S. Sekhar, R. Sivakumar, H. Kumar, and T. V. R. Ravi kumar, "Effect of aligned magnetic field on the steady viscous flow past a circular cylinder," Applied Mathematical Modelling, vol. 31, no. 1, pp. 130-139, 2007.

[20] D. G. E. Grigoriadis, I. E. Sarris, and S. C. Kassinos, "MHD flow past a circular cylinder using the immersed boundary method," Computers \& Fluids, vol. 39, no. 2, pp. 345-358, 2010.

[21] M. Tamoor, M. Waqas, M. I. Khan, A. Alsaedi, and T. Hayat, "Magnetohydrodynamic flow of Casson fluid over a stretching cylinder," Results in Physics, vol. 7, pp. 498-502, 2017.

[22] J.-H. Pan, M.-J. Ni, and N.-M. Zhang, "A consistent and conservative immersed boundary method for MHD flows and moving boundary problems," Journal of Computational Physics, vol. 373, pp. 425-445, 2018.

[23] J.-H. Pan, N.-M. Zhang, and M.-J. Ni, "Instability and transition of a vertical ascension or fall of a free sphere affected by a vertical magnetic field," Journal of Fluid Mechanics, vol. 859, pp. 33-48, 2019.

[24] J.-H. Pan, N.-M. Zhang, and M.-J. Ni, "Wake structure of laminar flow past a sphere under the influence of a transverse magnetic field," Journal of Fluid Mechanics, vol. 873, pp. 151-173, 2019.

[25] L. Chen, A. Pothérat, M. J. Ni, and R. Moreau, "Direct numerical simulation of quasi-two-dimensional MHD turbulent shear flows," Journal of Fluid Mechanics, vol. 915, 2021.

[26] R. Mahmood, S. Bilal, A. H. Majeed, I. Khan, and E.-S. M. Sherif, "A comparative analysis of flow features of newtonian and power law material: a new configuration," Journal of Materials Research and Technology, vol. 9, no. 2, pp. 1978-1987, 2019.

[27] S. Bilal, R. Mahmood, A. H. Majeed, I. Khan, and K. S. Nisar, "Finite element method visualization about heat transfer analysis of newtonian material in triangular cavity with square cylinder," Journal of Materials Research and Technology, vol. 9, no. 3, pp. 4904-4918, 2020.

[28] R. Mahmood, S. Bilal, A. H. Majeed, I. Khan, and K. S. Nisar, "CFD analysis for characterization of non-linear power law material in a channel driven cavity with a square cylinder by measuring variation in drag and lift forces," Journal of Materials Research and Technology, vol. 9, no. 3, pp. 3838-3846, 2020.

[29] R. Mahmood, S. Bilal, A. H. Majeed, I. Khan, and K. S. Nisar, "Assessment of pseudo-plastic and dilatant materials flow in channel driven cavity: application of metallurgical processes," Journal of Materials Research and Technology, vol. 9, no. 3, pp. 3829-3837, 2020.

[30] A. Mehmood, R. Mahmood, A. H. Majeed, and F. J. Awan, "Flow of the bingham-papanastasiou regularized material in a channel in the presence of obstacles: correlation between hydrodynamic forces and spacing of obstacles," Modelling and Simulation in Engineering, vol. 2021, no. April, 14 pages, Article ID 5583110, 2021.

[31] R. Mahmood, N. Kousar, K. Usman, and A. Mehmood, "Finite element simulations for stationary Bingham fluid flow past a circular cylinder," Journal of the Brazilian Society of Mechanical Sciences and Engineering, vol. 40, no. 9, pp. 1-9, 2018.

[32] A. H. Majeed, F. Jarad, R. Mahmood, and I. Saddique, "Topological characteristics of obstacles and nonlinear rheological fluid flow in presence of insulated fins: a fluid force reduction study," Mathematical Problems in Engineering, vol. 2021, Article ID 9199512, 15 pages, 2021.

[33] W. K. Hussam, M. C. Thompson, and G. J. Sheard, "Dynamics and heat transfer in a quasi-two-dimensional MHD flow past a circular cylinder in a duct at high Hartmann number," International Journal of Heat and Mass Transfer, vol. 54, no. 56, pp. 1091-1100, 2011. 
[34] Y. I. Cho and K. R. Kensey, "Effects of the non-Newtonian viscosity of blood on flows in a diseased arterial vessel. Part 1 : steady flows," Biorheology, vol. 28, no. 3-4, pp. 241-262, 1991. 